\title{
Pemanfaatan Notifikasi Telegram Untuk Monitoring Perangkat CCTV Rumah Sakit Orthopaedi Purwokerto
}

\author{
Khaidir Nalakhudin ${ }^{1}$ \\ Mohammad Imron ${ }^{2}$ \\ Muhamad Awiet Wiedanto Prasetyo ${ }^{3}$ \\ Universitas Amikom Purwokerto \\ Banyumas, Indonesia \\ E-mail:khaedrn@gmail.com ${ }^{1}$;imron@amikompurwokerto.ac.id 2; \\ mawp@amikompurwokerto.ac.id ${ }^{3}$
}

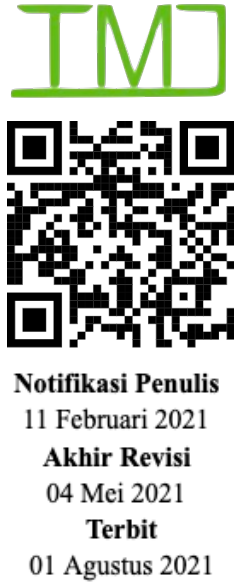

Nalakhudin, K., Imron, M., \& Wiedanto Prasetyo, M. A. . (2021). Pemanfaatan Notifikasi Telegram Untuk Monitoring Perangkat CCTV Rumah Sakit Orthopaedi Purwokerto.

Technomedia Journal, 6(1 Agustus).

https://doi.org/10.33050/tmj.v6i01 Agustus.1564

\begin{abstract}
ABSTRAK
Keamanan merupakan salah satu faktor terpenting dalam sebuah instansi maupun perusahaan. Dengan memanfaatkan teknologi CCTV (Closed Circuit Television) dapat mempermudah penggunaan, pemantauan, serta akses informasi di area-area tertentu. Permasalahan yang kerap terjadi adalah kurangnya pengawasan perangkat yang tidak dilakukan selama 24 jam. Pengawasan perangkat CCTV oleh teknisi hanya berjalan selama 14 jam yaitu dari jam 8 pagi sampai 10 malam.yang artinya diluar jam tersebut tidak ada pengawasan perangkat CCTV. Maka dari itu perlu adanya upaya untuk memonitor perangkat CCTV jika terjadi kendala yang menyebabkan perangkat tersebut tidak bekerja secara optimal. Penelitian ini bertujuan untuk membuat sistem monitor perangkat CCTV yang bermasalah dengan memanfaatkan notifikasi Telegram Bot secara realtime dan membantu teknisi dalam melakukan proses monitoring dan maintenance perangkat CCTV kemudian secara tidak langsung dan melakukan pengawasan kinerja karyawan. Sistem monitoring perangkat CCTV akan mengirimkan notifikasi via aplikasi Telegram yang berisi informasi nama perangkat, ip address perangkat, status perangkat, dan waktu deteksi perubahan status yang nantinya akan dikirimkan langsung ke teknisi untuk proses troubleshooting lebih lanjut.
\end{abstract}

Kata kunci : CCTV, Monitoring, Telegram, Bot

\section{ABSTRACT}

Security is one of the most important factors in an institution or company. By utilizing CCTV (Closed Circuit Television) technology, it can facilitate security, monitoring, and access to information in certain areas. The problem that often occurs is the lack of monitoring of the device which is not carried out for 24 hours. CCTV surveillance by technicians only runs for 14 hours, from 8 am to $10 \mathrm{pm}$, which means that outside these hours there is no CCTV 
surveillance. Therefore, it is necessary to have efforts to monitor CCTV devices if there are obstacles that cause the device to not work optimally. This study aims to create a CCTV device monitor system with problems using Telegram Bot notifications in realtime and assist technicians in monitoring and maintaining CCTV devices, and supervising employee performance.

Keywords: CCTV, Monitoring, Telegram Bot

\section{PENDAHULUAN}

Keamanan merupakan hal yang sangat penting. Berbagai cara dilakukan untuk meningkatkan keamanan. Teknologi keamanan yang banyak digunakan sekarang adalah CCTV (closedcircuit television). CCTV dapat memantau dan merekam segala aktivitas dan kejadian pada suatu tempat setiap saat. Ketersediaan CCTV di rumah sakit menjadi sangat penting dalam memonitor area yang krusial seperti antrian pasien, ruang tunggu, area parkir, ruang kerja, pintu masuk, pintu keluar, kantin dan lain-lain. Atas dasar tersebut, monitoring terhadap perangkat CCTV sangatlah penting untuk menjaga stabilitas perangkat agar berjalan dengan optimal [10]. Monitoring perangkat CCTV yang tersambung didalam jaringan internal rumah sakit yang diatur oleh router MikroTik. MikroTik juga menyediakan fasilitas software yang digunakan untuk alat bantu dalam pengelolaan system dan network infrastruktur yang dinamakan "The Dude".

The Dude adalah perangkat lunak yang berfungsi untuk memonitoring jaringan yang merupakan bawaan dari MikroTik. The Dude memiliki beberapa peralatan yang dapat berfungsi untuk melihat perangkat yang aktif dalam suatu jaringan dan dilengkapi dengan tampilan map perangkat yang aktif dalam jaringan, juga fasilitas seperti http, telnet, ping, terminal, torch, bandwith management, dan lain sebagainya [8]. The Dude didesain untuk mewakilkan struktur dari sebuah jaringan yang membolehkan pengguna untuk memuat skema dari jaringan yang tersebut, baik secara manual maupun menggunakan automatic network discovery tool [9].

Penggunaan The Dude sebagai monitoring perangkat CCTV secara realtime dapat dilakukan dengan memanfaatkan Telegram Bot sebagai notifikasinya, Telegram adalah sebuah aplikasi yang memungkinkan pengguna atau user untuk mengirim pesan dengan cepat dan aman, selain itu salah satu fitur Telegram yang sering dimanfaatkan oleh pengembang adalah fitur Telegram Bot [5]. Telegram Bot merupakan akun khusus yang tidak memerlukan nomor telepon tambahan untuk didaftarkan ke Server Telegram. Akun ini berfungsi sebagai antarmuka antara kode program dengan server Telegram [3]. Berikut beberapa keunggulan aplikasi Telegram yaitu mengirim pesan lebih cepat karena berbasis cloud, lebih ringan dijalankan dan dapat diakses dari berbagai perangkat [1].

\section{PERMASALAHAN}

Permasalahan pada Rumah Sakit Orthopaedi Purwokerto saat ini adalah seperti berikut:

a) Monitoring perangkat CCTV yang tidak dilakukan selama 24 jam

b) SDM yang terbatas untuk melakukan monitoring perangkat CCTV secara realtime

c) Teknisi sulit untuk melakukan troubleshooting perangkat yang bermasalah

\section{METODOLOGI PENELITIAN}

1. Metode Penelitian

Metode penelitian yang digunakan dalam penelitian ini menggunakan metode tindakan 
atau action research. Metode penelitian tindakan atau action research merupakan metode yang digunakan untuk menguji, mengembangkan, menemukan dan menciptakan tindakan baru, sehingga tindakan tersebut jika diterapkan dalam pekerjaan, maka proses pelaksanaan kerja akan lebih mudah, lebih cepat, dan hasilnya lebih banyak dan berkualitas. Tahapan penelitian dari action research ini adalah Diagnosing, Action Planning, Action Taking, Evaluating, dan Learning[7].

\subsection{Diagnosing}

Diagnosa atau diagnosis merupakan tahap identifikasi masalah-masalah pokok yang sedang terjadi. Pada tahap ini peneliti melakukan analisa mendalam terhadap permasalahan, dari data yang sudah ada sebelumnya melalui wawancara, observasi, studi pustaka dan dokumentasi[7]. Berdasarkan hasil diagnosa permasalahan yang ada di Rumah Sakit Orthopaedi Purwokerto bahwa proses monitoring perangkat CCTV yang tidak dilakukan selama 24 jam akan dapat mengganggu mengenai keamanan, dan pengawasan. Maka perlu adanya sistem monitoring perangkat CCTV yang bekerja secara realtime selama 24 jam.

\subsection{Action Planning}

Membuat rencana tindakan (action planning) merupakan tahapan yang dilakukan dengan memahami pokok masalah yang ada pada tahap diagnosa (diagnosing)[7]. Selanjutnya menyusun rencana tindakan yang tepat dalam menyelesaikan masalah yang akan dilakukan pada proses pemantauan dan monitoring perangkat CCTV di Rumah Sakit Orthopaedi Purwokerto dengan membuat perancangan pengaplikasian The Dude dan implementasi notifikasi Telegram. Adapun Rencana tindakan yang dilakukan berdasarkan pokok permasalahan hasil diagnosa adalah sebagai berikut :

a) Melakukan instalasi The Dude server pada Router MikroTik

b) Melakukan instalasi The Dude client pada komputer

c) Melakukan device scanning pada aplikasi The Dude

d) Melakukan konfigurasi device serta implementasi Telegram Bot

Melakukan pengujian perangkat CCTV dengan mematikan daya untuk mengetahui sistem monitoring sudah berjalan sesuai dengan yang diinginkan. Cara kerja sistem yang melakukan ping secara berkala ke perangkat yang tersambung akan secara otomatis mengirimkan action berupa notifikasi Telegram ketika proses ping tidak mendapatkan feedback dari perangkat

2. Teknik Pengumpulan Data

Beberapa teknik pengumpulan data yang digunakan dalam penelitian ini adalah sebagai berikut :

\section{A. Observasi}

Yaitu mendapatkan data melalui pengamatan yang dilakukan secara langsung[11]. Pada tahap observasi, peneliti melakukan pengamatan terhadap kondisi lapangan, yang terdiri dari pengamatan perangkat CCTV, jumlah perangkat, lokasi penempatan CCTV, topologi jaringan, dan konfigurasi IP yang digunakan. Lebih lanjut peneliti juga melakukan pengamatan yang mendalam terhadap dampak yang ditimbulkan jika terdapat salah satu perangkat yang mengalami kendala, mulai dari proses pengecekan sampai dengan proses perbaikan. 
B. Wawancara

Pengumpulan data dengan melakukan komunikasi dua arah untuk mendapatkan data dari responden[12]. Pada tahap ini peneliti melakukan wawancara kepada Manajer IT dalam memonitoring CCTV dan juga keamanan di Rumah Sakit Orthopaedi Purwokerto guna mencari informasi mengenai kebutuhan yang melandasi pembuatan notifikasi monitoring perangkat CCTV. Seperti faktor utama yang menjadikan CCTV sebagai perangkat yang penting di dalam Rumah Sakit Orthopaedi Purwokerto dari segi keamanan, pengawasan karyawan, dan monitoring rutin yang harus dijaga keberlangsungan fungsionalitasnya

C. Studi Pustaka

Studi pustaka digunakan dalam mencari landasan teori dari macam-macam sumber yang berhubungan dengan masalah penelitian dengan cara membaca buku-buku perpustakaan, panduan, serta literatur lain yang berkaitan[13].

D. Dokumentasi

Dokumentasi digunakan untuk mengumpulkan data kemudian ditelaah[14]. Dokumentasi yang digunakan dalam penelitian ini meliputi informasi CCTV berupa ip address, letak cctv dan nama perangkat.

\section{Literatur Review}

Sistem monitoring yang pernah dibuat, berkaitan dengan penelitian ini adalah sebagai berikut:

3.1.Penelitian [2] dalam penelitiannya yang berjudul "Sistem Monitoring Jaringan PT Exhibition Network Indonesia dengan The Dude berbasis MikroTik". Dalam penelitian ini peneliti menyimpulkan bahwa sistem monitoring jaringan di PT Exhibition Network Indonesia penggunaan Network Monitoring Management System (NMS) yang baik dapat mengurangi atau meminimalkan troubleshooting yang terjadi di perangkat yang tersambung kedalam jaringan, berdasarkan grafik data yang termonitor secara real time dengan memanfaatkan fitur Simple Mail Transfer Protocol (SMTP). Hasil dari penelitian ini adalah fitur notifikasi via email yang dapat membantu memonitoring perangkat yang tersambung ke dalam jaringan.

3.2.Penelitian [4] dalam penelitiannya yang berjudul "Pemanfaatan Notifikasi Telegram Untuk Monitoring Jaringan". Penelitian ini bertujuan untuk memanfaatkan notifikasi telegram dalam memonitoring jaringan pada suatu server dan untuk mengetahui kondisi server secara realtime. Metode penelitian yang digunakan dalam penelitian ini menggunakan metode tindakan atau action research, dan tahapan yang dilakukan adalah Diagnosing, Action Planning, Action Taking, Evaluating, dan Learning. Hasil dari penelitian ini adalah fitur notifikasi via Telegram jika terjadi serangan pada server secara realtime.

3.3.Penelitian [6] dalam penelitiannya yang berjudul "Perancangan Sistem Monitoring Perangkat Jaringan Berbasis ICMP dengan Notifikasi Telegram". Penelitian ini bertujuan untuk memonitoring dan menganalisa perangkat-perangkat yang tersambung melalui jaringan internet guna menjaga kestabilan jaringan komputer. Lokasi penelitian ini berada di SMK NU Kaplongan. Dengan memanfaatkan protokol ICMP (Internet Control Message Protocol) serta Telegram Bot untuk pengiriman pesan notifikasi ketika perangkat yang terputus dari jaringan, dapat membantu mengidentifikasi perbaikan terhadap gangguan yang terjadi pada jaringan serta membantu Network Administrator dalam menjaga jaringan.

\section{HASIL DAN PEMBAHASAN}




\section{Action Taking}

Bagian ini menjelaskan tentang proses instalasi serta konfigurasi yang harus dilakukan terlebih dahulu untuk membentuk sistem monitoring sebelum melakukan pengujian.

1.1 Instalasi The Dude Server di MikroTik

Untuk melakukan instalasi The Dude Server pada MikroTik dibutuhkan package yang harus disesuaikan dengan seri dan versi dari MikroTik yang digunakan, dengan tahapan instalasi sebagai berikut :

a) Mengunduh package The Dude Server pada website resmi MikroTik

b) Mengunggah package ke MikroTik menggunakan Winbox

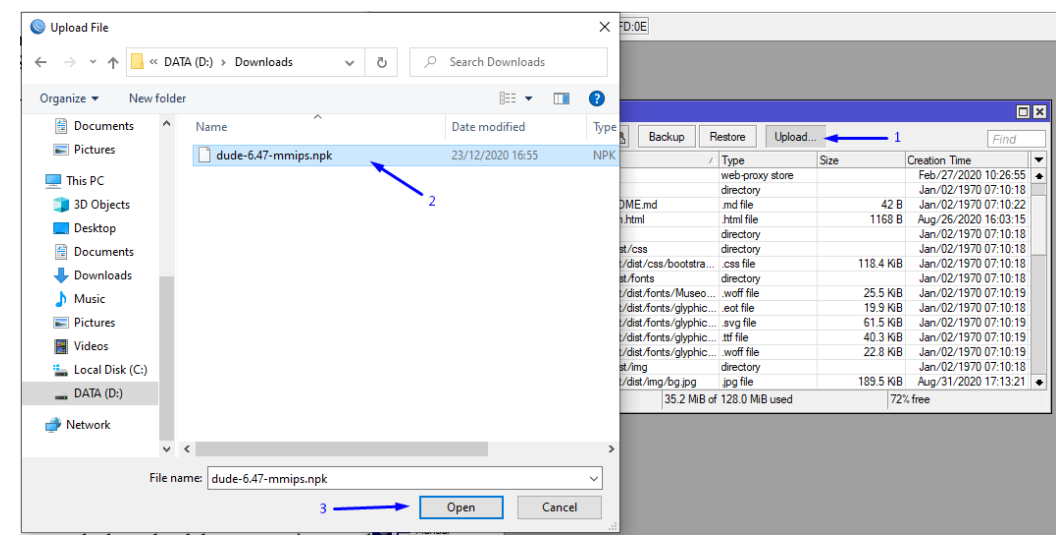

Gambar 1 Instalasi The Dude

Pada gambar 1 proses instalasi The Dude Server dilakukan dengan mengunggah package yang sudah. Setelah dilakukan pengunggahan pada MikroTik langkah selanjutnya yaitu dengan me-reboot perangkat tersebut.

1.2 Instalasi The Dude Client

Untuk dapat mengakses The Dude Server pada MikroTik dibutuhkan aplikasi The Dude Client yang terinstal di komputer lokal, dan harus satu jaringan dengan MikroTik. File installer dapat diunduh di halaman yang sama dengan mengunduh The Dude Server

1.3 Melakukan Device Scanning

Pada tahap ini, akan dilakukan proses pencarian perangkat CCTV yang akan dimonitoring. Di Bagian menu The Dude pilih Discover kemudian memasukan class ip CCTV. 


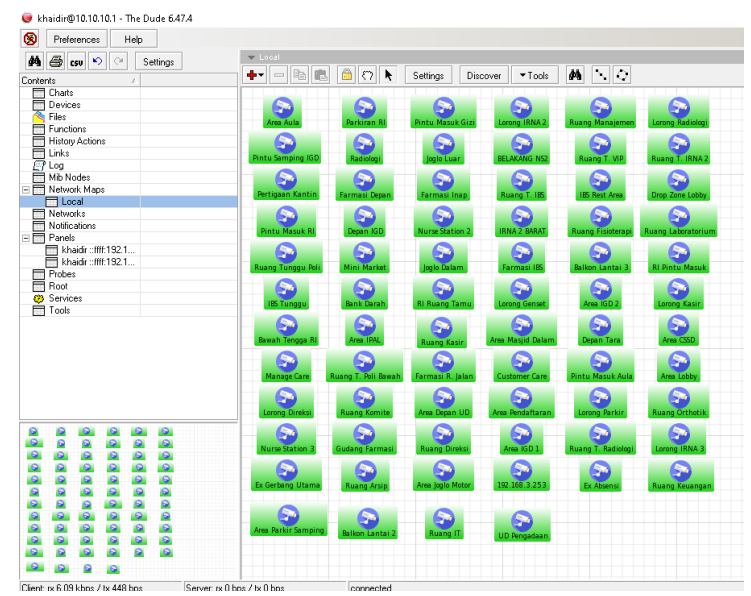

Gambar 2 Hasil scanning device CCTV

1.4 Melakukan konfigurasi device serta implementasi Telegram Bot

Untuk membuat Bot penggunakan harus memiliki akun yang sudah terdaftar pada Aplikasi Telegram, kemudian pengguna melakukan permintaan kepada @,BotFather untuk mendapatkan username, token dan id chat user.

Tabel 1 Telegram bot informasi

\begin{tabular}{|l|l|}
\hline nama grup & CCTVMonitoring System \\
\hline nama bot & CCTVMonitoring System \\
\hline username bot & @cctvmonitoring_bot \\
\hline token bot & 1426944741:AAFSQjasFr4bnOvInMcZYVMCm1uk93Afih4 \\
\hline id chat & -1001475030495 \\
\hline
\end{tabular}

1.5 Melakukan konfigurasi device serta implementasi Telegram Bot pada Trigger

Trigger merupakan pemicu yang akan mengeksekusi sebuah perintah secara otomatis untuk menanggapi perubahan tertentu. Implementasi ini perlu adanya kode program (script) untuk menghubungkan Telegram Bot dengan The Dude agar mendapatkan notifikasi dari aplikasi Telegram . Saat terjadi perubahan status perangkat , trigger akan secara otomatis memberikan respon dengan mengirimkan notifikasi ke aplikasi telegram.

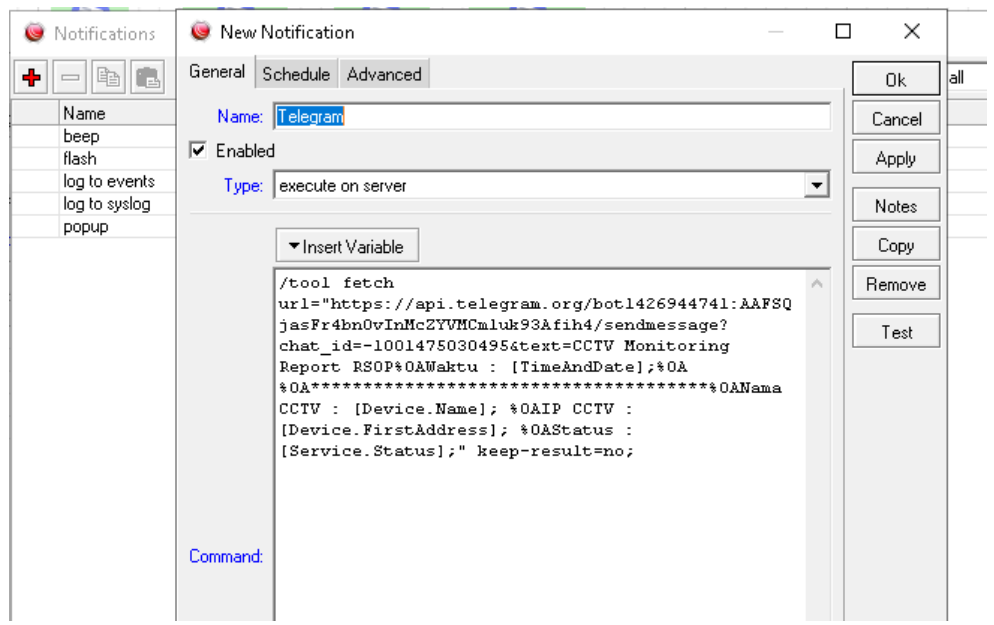

Gambar 3 Penambahan trigger Telegram bot

1.6 Melakukan Pengujian 
Pengujian dilakukan pada sistem yang sudah diimplementasi untuk mengetahui apakah kinerjanya dapat berjalan dengan baik atau tidak. Dalam pengujian ini akan dilakukan dengan mematikan daya CCTV untuk menguji apakah notifikasi akan terkirim ketika service tidak ada respon dari perangkat. Ketika service mendapatkan respon maka akan mengirimkan status up, jika service tidak mendapatkan respon maka akan mengirimkan status down. Dalam pengujian ini juga dilakukan pengukuran responsifitas dari ketiga service yang ada yaitu http, ping, dan telnet.
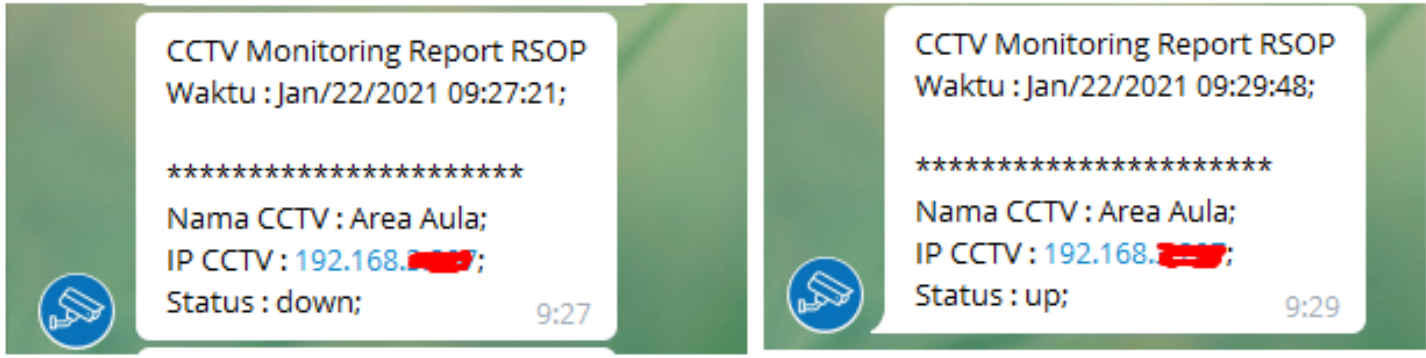

Gambar 4 Notifikasi status down dan up pada telegram dengan service ping

Pada gambar 4 dilakukan pengujian dengan service ping pada tanggal 22 Januari 2021 jam 09:25:00, dan setelah terdeteksi bahwa perangkat CCTV tersebut tidak tersambung maka otomatis mengirimkan notifikasi down pada jam 09:27:21. Pada jam 09:29:00 daya kembali disambungkan dan service ping kembali berjalan yang mengirimkan notifikasi up pada jam 09:29:44
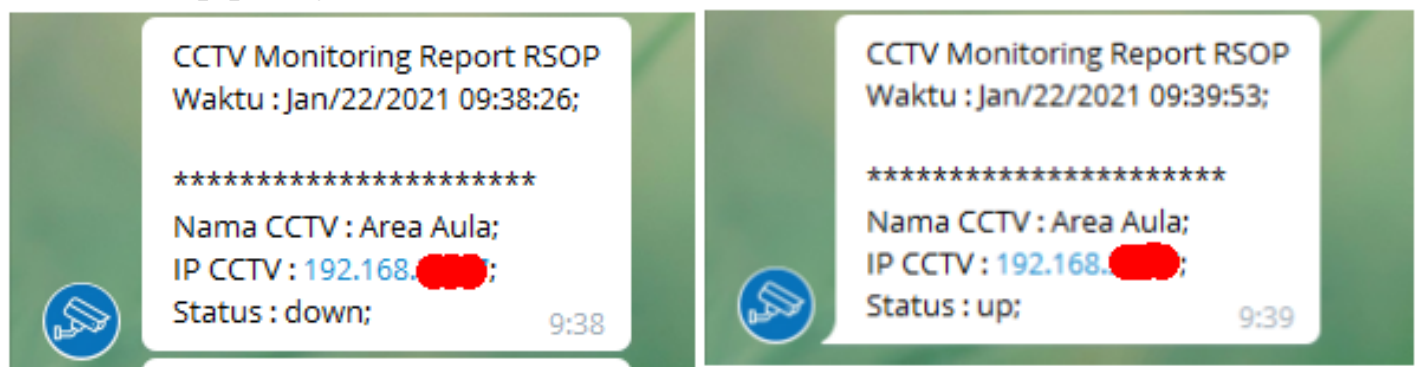

Gambar 5 Notifikasi status down dan up pada telegram dengan service http

Pada gambar 5 dilakukan pengujian dengan service http pada tanggal 22 Januari 2021 jam 09:36:00, dan setelah terdeteksi bahwa perangkat CCTV tersebut tidak tersambung, notifikasi telegram terkirim pada jam 09:38:26. Pada jam 09:39:00 daya kembali disambungkan dan service http kembali berjalan yang mengirimkan notifikasi up pada jam 09:39:53
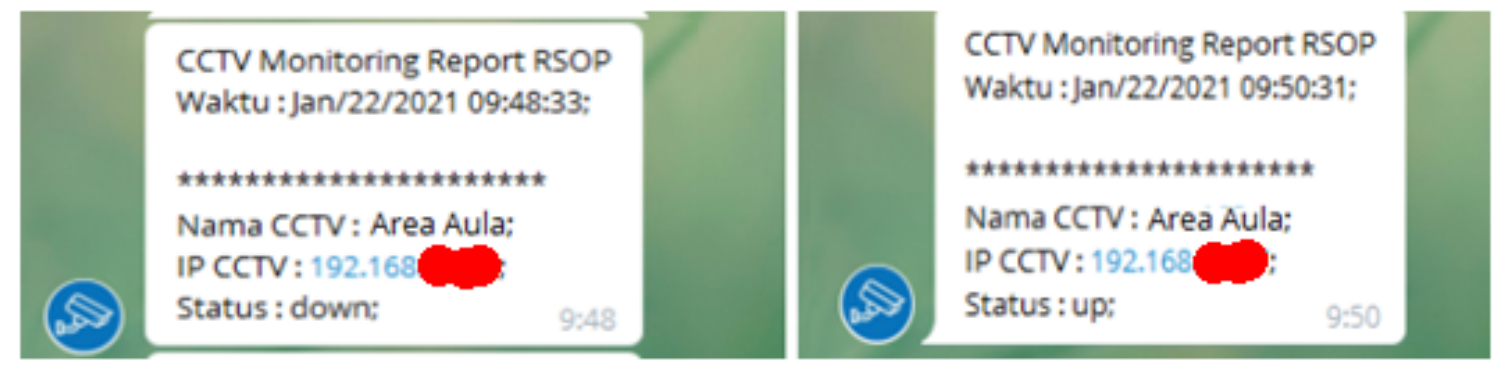

Gambar 6 Notifikasi status down dan up pada telegram dengan serice telnet

Pada gambar 6 dilakukan pengujian dengan service http pada tanggal 22 Januari 2021 jam 09:46:00, dan setelah terdeteksi bahwa perangkat CCTV tersebut tidak tersambung, notifikasi telegram terkirim pada jam 09:48:33. Pada jam 09:50:00 daya kembali 
disambungkan dan service http kembali berjalan yang mengirimkan notifikasi up pada jam 09:50:31

Data hasil perhitungan dari tabel 4.4, terlihat ketiga pengujian service yang dilakukan, memiliki rata-rata waktu yang dibutuhkan untuk mendeteksi bahwa perangkat CCTV tersebut down adalah 2 menit 26 detik dan waktu yang dibutuhkan untuk mengirimkan notifikasi bahwa perangkat cctv up adalah 42 detik, sedangkan waktu yang dibutuhkan untuk mengirimkan notifikasi telegram setelah terdeteksi adalah 0 detik.

Tabel 2 Hasil pengujian

\begin{tabular}{|c|c|c|c|c|c|}
\hline \multirow[b]{2}{*}{ No. } & \multirow[b]{2}{*}{$\begin{array}{l}\text { Pengujian } \\
\text { Service }\end{array}$} & \multirow{2}{*}{$\begin{array}{l}\text { Tipe } \\
\text { Pengujia } \\
n\end{array}$} & \multicolumn{3}{|l|}{ Waktu } \\
\hline & & & $\begin{array}{l}\text { Awal } \\
\text { Pengujian }\end{array}$ & Terdeteksi & Terkirim \\
\hline 1. & http & down & 09:36:00 & $09: 38: 26$ & $09: 38: 26$ \\
\hline 2. & ping & down & $09: 25: 00$ & $09: 27: 21$ & $09: 27: 21$ \\
\hline 3. & telnet & down & $09: 46: 00$ & $09: 48: 33$ & $09: 48: 33$ \\
\hline 4. & http & up & 09:39:00 & 09:39:53 & 09:39:53 \\
\hline 5. & ping & up & 09:29:00 & $09: 29: 44$ & $09: 29: 44$ \\
\hline 6. & telnet & up & 09:50:00 & $09: 50: 31$ & $09: 50: 31$ \\
\hline
\end{tabular}

\section{Evaluating}

Setelah dilakukan tahapan action taking, maka untuk meningkatkan kinerja dan performa dari sistem monitoring perangkat CCTV, perlu adanya evaluasi untuk mengetahui beberapa respon yang dapat dideteksi oleh sistem. Dari hasil evaluasi, waktu yang dibutuhkan untuk mendeteksi bahwa perangkat CCTV itu down adalah lebih dari dua menit, hal tersebut dapat terjadi dikarenakan transisi status service dari up ke down atau sebaliknya membutuhkan waktu sekitar dua menit. Transisi itu disebut dengan status unstable (tidak stabil), kondisi ini disebabkan oleh masalah koneksi perangkat CCTV yang tidak stabil dan menyebabkan services tidak berjalan seperti semestinya yang kemudian baru berganti status menjadi down setelah kurang lebih dua menit. Untuk meningkatkan waktu pendeteksian perangkat yang mengalami masalah, perlu penambahan trigger berupa unstable yang nantinya akan mengirimkan notifikasi ketika status service dari up berubah ke unstable maupun sebaliknya dan dari down berubah ke unstable maupun sebaliknya

\section{Learning}

Dengan adanya notifikasi yang dikirimkan secara otomatis melalui aplikasi telegram saat terjadi gangguan pada perangkat CCTV menjadi suatu hal yang sangat penting. Teknisi dapat mengetahui tentang kondisi perangkat CCTV dengan lebih cepat menggunakan service ping. Disisi lain penerapan sistem monitoring dengan notifikasi telegram ini dan penambahan trigger unstable juga dapat mempercepat pendeteksian yang dapat dijadikan sebagai acuan bagi teknisi untuk mengambil tindakan selanjutnya

\section{KESIMPULAN}

Kesimpulan yang dapat diambil dari pembuatan Sistem Monitoring Perangkat CCTV dengan mengimplementasikan Telegram Bot sebagai notifikasinya adalah sistem monitoring perangkat CCTV ini dapat membantu teknisi dalam mencari titik yang terjadi gangguan pada perangkat CCTV di Rumah Sakit Orthopaedi Purwokerto, mempermudah dalam proses troubleshooting perangkat CCTV dan dapat melakukan monitoring perangkat CCTV selama 
24 jam secara realtime. Sementara itu dibanding dengan penelitian sebelumnya, penambahan trigger unstable dapat mempercepat pendeteksian status perangkat yang mengalami kendala.

\section{SARAN}

Berdasarkan kesimpulan dan pembahasan diatas maka dihasilkan sebuah sistem monitoring perangkat CCTV dengan menggunakan notifikasi telegram secara realtime yang berperan dalam mempermudah teknisi dalam melakukan pengawasan dan pemantauan kondisi perangkat CCTV di Rumah Sakit Orthopaedi Purwokerto. Pengembangan sangat diperlukan sesuai dengan kebutuhan yang terus bertambah. Untuk itu penulis memberikan saran yang dapat digunakan sebagai bahan pertimbangan untuk penelitian selanjutnya yaitu melakukan pengembangan terhadap sistem monitoring dari segi waktu pendeteksian dan menambahkan fitur laporan hasil monitoring yang disimpan dalam database.

\section{DAFTAR PUSTAKA}

[1] F. Fitriansyah, "Penggunaan Telegram Sebagai Media Komunikasi Dalam Pembelajaran Online," Cakrawala-Jurnal Humaniora, vol. 20, no. 2, pp. 111-117, 2020.

[2] A. Idrus, "Sistem Monitoring Jaringan PT. Exhibition Network Indonesia DenganThe Dude Berbasis Mikrotik," INFORMATICS FOR EDUCATORS AND PROFESSIONAL: Journal of Informatics, vol. 1, no. 1, pp. 84-93, 2016.

[3] R. Nufusula and A. Susanto, "Rancang Bangun Chat Bot Pada Server Pulsa Mengunakan Telegram Bot API," JOINS (Journal of Information System), vol. 3, no. 1, pp. 80-88, 2018.

[4] F. Panjaitan and R. Syafari, "Pemanfaatan Notifikasi Telegram Untuk Monitoring Jaringan," Simetris: Jurnal Teknik Mesin, Elektro dan Ilmu Komputer, vol. 10, no. 2, pp. 725-732, 2019.

[5] H. Soeroso, A. Z. Arfianto, N. E. Mayangsari, and M. Taali, "Penggunaan Bot Telegram Sebagai Announcement System pada Intansi Pendidikan," in Seminar Master PPNS, 2017, vol. 2, no. 1, pp. 45-48.

[6] Z. Fauziah, H. Latifah, X. Omar, A. Khoirunisa, and S. Millah, "Application of Blockchain Technology in Smart Contracts: A Systematic Literature Review," Aptisi Transactions on Technopreneurship (ATT), vol. 2, no. 2, pp. 160-166, 2020.

[7] B. D. Wicaksono and S. Anggraeni, "Perancangan Website Sistem Informasi Transaksi Tagihan Layanan Purna Jual Properti Pada Pollux Properti Indonesia," TMJ (Technomedia Journal) Vol. 5 No. 2 Februari 2021, p. 132, 2021.

[8] P. Sugiyono, "Metode penelitian kombinasi (mixed methods)," Bandung: Alfabeta, 2015.

[9] R. Rosyid and M. A. W. Prasetyo, "Robot Peraga 12 Gerakan Pengaturan Lalu Lintas Berbasis Arduino Mega 2560,” Technomedia Journal, vol. 5, no. 2, pp. 193-205, 2021.

[10] S. Rahayu, A. Setiadi, and A. Muryanto, "Perancangan Sistem Pendaftaran Siswa Baru Secara Online Pada SMK Miftahul Jannah Cikupa," Technomedia Journal, vol. 5, no. 2, pp. 235-247, 2021.

[11] S. Sutarti and A. Alfiyansyah, "Analisis dan Implementasi Sistem Monitoring Koneksi Internet Menggunakan The Dude Di STIKOM Al Khairiyah," JSiI (Jurnal 
Sistem Informasi), vol. 4, 2017.

[12] A. Widodo, "Implementasi Monitoring Jaringan Komputer Menggunakan Dude," Jurnal Teknologi Informasi, vol. 11, no. 1, 2017.

[13] N. Cholisoh, J. Junaidi, and I. S. Sari, "Rancangan Sistem Penginputan Judul Online KKP, TA/SKRIPSI Berbasis Laravel Pada Universitas Raharja," Technomedia Journal, vol. 5, no. 2, pp. 248-258, 2021.

[14] P. Sokibi, "Perancangan Sistem Monitoring Perangkat Jaringan Berbasis ICMP dengan Notifikasi Telegram," Cirebon: STMIK CIC, 2017.

[15] D. Cahyadi, A. Faturahman, H. Haryani, and E. Dolan, "BCS: Blockchain Smart Curriculum System for Verification Student Accreditation," International Journal of Cyber and IT Service Management, vol. 1, no. 1, pp. 65-83, 2021.

[16] I. Muhamad, W. Hidayat, and I. Handayani, "Perancangan Sistem Informasi Persediaan Barang Pada PT. Pacific Paint Menggunakan PHP dan MySQL," Technomedia Journal, vol. 5, no. 2, pp. 182-192, 2021.

[17] L. Munaroh, Y. Amrozi, and R. A. Nurdian, "Pengukuran Risiko Keamanan Aset TI Menggunakan Metode FMEA dan Standar ISO/IEC 27001: 2013," Technomedia Journal, vol. 5, no. 2, pp. 167-181, 2021.

[18] E. Febriyanto, T. Triyono, N. Rahayu, and R. Nurbaiti, "QRcode Verifikasi Sertifikat Sebagai Bukti Keabsahan Dokumen dalam Bidang Pendidikan," Technomedia Journal, vol. 5, no. 1 Agustus, pp. 96-105, 2020.

[19] J. Hartono, "Metodologi Penelitian Bisnis: salah kaprah dan pengalamanpengalaman," Yogyakarta: Bpfe, 2004.

[20] M. Nazir, "Metode Penelitian, Bogor: Ghalia Indonesia," Jurnal Pendidikan Agama Islam, 2005. 